\section{OBSERVAR É PRECISO: A GIDADE E OS "ILUSTRES HÓSPEDES"}

\author{
Joyce Mota Rodrigues
}

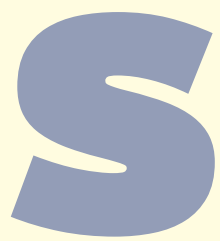

obral, Ceará, maio de 1919. Parecia ser uma manhã de sol como outra qualquer, supostamente pacata e monótona. Vizinhos nas calçadas conversando, comentando assuntos e "causos" sobre o cotidiano da cidade. Na cozinha, moradores enchiam suas canecas com café quentinho tirado do bule; outros debulhavam o feijão que seria servido no almoço e no jantar com alguma "mistura"; alguns mascavam fumo ao dirigirem-se para a "lida"; e havia aqueles que liam o jornal com as notícias sobre a região Nordeste.

A cidade estava movimentada como era de costume, contudo as conversas com tons de sabedoria e adivinhação sobre o que aconteceria naquele mês eram recorrentes. Cada um, à sua maneira, procurava entender e explicar aos demais o que estaria por vir. Afinal, não era todo dia que visitantes de outros países e do Rio de Janeiro chegavam a Sobral em busca de conhecer e intervir numa cidade que, apesar do acesso por ferrovia, não possuía eletricidade, tampouco atrativos para tal visitação.

"Homens da ciência" mobilizados; um político da região que cederia sua casa para estrangeiros acomodarem-se [1] providenciava para eles água em abundância; bagagens que não paravam de chegar à área interna do Jockey Club [2], suspendendo as corridas de cavalos no hipódromo, com objetos nunca vistos na cidade; pedreiros trabalhando arduamente para melhor instalar os instrumentos trazidos de além-mar; uma série de recomendaçôes publicadas nos jornais sobre como a população deveria se comportar no dia em que o eclipse seria observado e registrado. Alguns desses visitantes não falavam coisa que se pudesse compreender - um engenheiro, aparentemente o único habitante da cidade que falava inglês, passou a acompanhá-los [3]. Tal movimentação era diferente. Extraordinária!

O cotidiano dá lugar ao incomum, o evento que ficou conhecido como "o eclipse solar de 1919". É provável que o evento em si —o eclipse total do Sol - não tenha sido assim tão inusitado. Outros eclipses aconteceram antes desse. Possivelmente, os instrumentos suntuosos, pesados e embalados em grandes caixotes tenham causado mais espanto e indagaçóes. Os jornais explicitavam a expectativa com relação aos astrônomos, cientistas ou "ilustres hóspedes". Os observadores mostravam os aparelhos à população, tentavam explicar para que serviam e o motivo pelo qual eles estavam ali na cidade. Tudo era motivo para perguntas.

Este artigo vem de uma pesquisa [4] que se refere ao avanço ocorrido na história da ciência nas primeiras décadas do século XX. Situa-se na cidade de Sobral [5], localizada no interior do estado brasileiro do Ceará. Na pesquisa, analiso a documentação produzida pelos membros das expediçôes expondo o percurso da viagem, a acomodação dos viajantes na cidade e o processo de obtençáo dos dados acerca do eclipse. As expediçōes eram compostas por estudiosos - chamados cordialmente de visitantes e cientistas pela população - que foram à Sobral observar e registrar por meio de chapas fotográficas o eclipse solar de 1919.

A partir da observação desse fenômeno foi possível localizar a posição das estrelas, pois a claridade do Sol estaria ofuscada pela Lua para que, assim, se pudesse verificar, experimentalmente, a hipótese da relatividade geral proposta pelo físico alemão Albert Einstein (1879-1955) em 1915. A confirmação do desvio da luz, a partir da observação do eclipse total do Sol em 1919 é considerada pela comunidade científica um dos mais importantes acontecimentos da história da ciência.

Diante de tal configuração, são necessárias algumas explanaçōes para entender quem eram esses estrangeiros, qual a utilidade dos instrumentos e o que significou esse evento. Também, a compreensão de que o cotidiano local foi modificado a partir da história de um "encontro": dos observadores integrantes das expediçōes científicas (britânica, brasileira e norte-americana) com a população local e, por outro lado, da cidade com as comitivas.

As três expedições possuíam objetivos distintos, eram trabalhos astronômicos e geofísicos com interesses específicos. A expedição britânica, enviada pelo Observatório de Greenwich, na Inglaterra, propôs-se elucidar a teoria da relatividade publicada por Albert Einstein em 1915. A expedição brasileira, além de obter dados sobre a coroa solar, tinha a missão de aperfeiçoar a estação de meteorologia. Henrique Morize, chefe do grupo brasileiro, havia estado em Sobral três meses antes para iniciar o processo de instalação. Esse empreendimento correspondia a uma demanda do Observatório Nacional do Rio de Janeiro e a estação foi aprimorada pelos pesquisadores da instituição a serviço do governo federal [6]. A expedição norte-americana, por iniciativa de Louis Bauer, diretor do Departamento de Magnetismo Terrestre do Instituto Carnegie, além de estudar os efeitos do eclipse sobre o magnetismo terrestre e a eletricidade atmosférica, cederia alguns instrumentos para a expedição brasileira e, após a publicação dos resultados, somaria aos estudos da última [7].

As fontes descritas nesta pesquisa, a saber, jornais [8], relatórios [9], diário [10], revistas [11], bem como a publicação dos resultados da experiência por meio de um relatório escrito tanto por membros das expedições que foram à Sobral, como também pelos observadores que foram para a Ilha do Príncipe [12], são relevantes para a reflexão acerca das tensões entre diferentes possibilidades para a escrita das expedições do eclipse solar e seu "encontro" com a cidade de Sobral.

Tais fontes foram organizadas, levando-se em consideração os seguintes temas: escolha do lugar, organização das expediçôes (integrantes, instituições, financiamento), viagem, desembarque, comentários da população de Sobral sobre o evento, impressōes dos 
terrestre como também fazer um último ajustamento nos mecanismos de velocidade dos relógios". Com o reaparecimento do Sol e a calibragem dos instrumentos, as séries de fotografias da coroa solar foram plenamente executadas, conforme planejado: "O programa que preparámos foi realizado com sucesso: expuseram-se 19 chapas no telescópio astrográfico, com exposições alternativas de cinco e 10 segundos, e oito chapas na câmara de quatro polegadas, com um tempo de exposição uniforme de 28 segundos" ([19], p. 79).

POR FIM, 0 ECLIPSE "Nesse momento a população já se adensava pelas praças, num vosear rumoroso, e braços sem conta apontavam para o Sol" [15]. A expectativa e ansiedade faziam com que os bondes minúsculos da empresa Thaumaturgo, “[...] apressados e sacolejantes, despejavam, a curto espaço, na Praça do Patrocínio, onde a multidão se espremia em volta do acampamento dos astrônomos brasileiros, dezenas de curiosos" [15]. Às 7h46 foi registrado o primeiro momento do eclipse, "[...] através de uns delgados farrapos de nuvem, o Sol tornou-se visível, e o primeiro contacto exterior do belíssimo phenomeno foi observado" [15].

O mau tempo, contudo, provocava ansiedade até o momento da totalidade do eclipse:

Ao aproximar-se a fase de eclipse total, a proporção de nebulosidade diminuiu e assistiu-se a uma clareira extensa na região do Sol, cerca de um minuto antes do segundo contacto. Os avisos foram dados a 58, 22 e 12 segundos antes do segundo contacto através da observação da diminuição da forma em quarto crescente na lente colocada no local de observação. Ao desaparecer a forma de quarto crescente, deu-se início à observação com a palavra $<<$ Começar $>>$. A região em redor do Sol estava sem nuvens, exceptuando um período que durou cerca de um minuto, precisamente a meio da fase de totalidade. Nesse instante, o Sol ficou ligeiramente velado por uma nuvem pouco espessa, que impediu a tiragem de fotografias às estrelas; contudo, a coroa solar interior permaneceu visível a olho nu e as chapas expostas durante esta fase revelam-na, com uma grande proeminência muito bem definida ([19], p. 79-80).

A temperatura caiu no momento da totalidade do eclipse: "O thermometro desceu [...] O silêncio fez-se absoluto, permitindo ouvir-se nitidamente os estalidos seccos dos detetores das machinas photographicas, dentro do acampamento. [...] Rápidos 5 minutos!" [15].

Importante destacar que o evento astronômico foi marcado pela ansiedade e por problemas no funcionamento dos aparelhos. $\mathrm{O}$ clima quente afetou não só os observadores, com noites mal dormidas, mas também os materiais. Morize em seu relatório anotou em diversos momentos [20].

A reação de populares, animais e plantas não foi passiva. Mesmo com todas as recomendações para a observação do fenômeno, "[...] foi uma coisa de doido o dia do eclipse, aqui em Sobral" [14].
Não só em Sobral. Em Nova-Russas, as reações ao eclipse foram enviadas ao jornal $A$ Lucta: "Durou a totalidade do eclipse um a dois minutos; as andorinhas em bando rodeiaram a nossa egreginha para se recolherem; as galinhas ainda curvaram as cabeças estirando os pescoços, mas não chegaram a subir os poleiros" [17]. Parte dos habitantes desses municípios reproduzia o temor de ver o dia transformar-se em noite. A experiência pretérita do fenômeno estava carregada de histórias de que o mundo iria acabar. Já os observadores tentavam tranquilizar a população com explicaçōes científicas que naturalizariam o extraordinário: "O eclipse solar é um facto natural, destituído de quaisquer consequências nocivas. Não anuncia pestes, nem secas, nem inundaçôes" [21]. Como conciliar concepções arcaicas, de tom sobrenatural, com o rigor e a postura exigida pela ciência?

A partir dessas questōes, surgiram situaçōes de maior ou menor conflito. Estratégias de organização coletiva e individual foram postas em prática. Muitas vezes, as recomendaçôes estavam mascaradas em regras postas de "cima para baixo": "Assim fazendo, os habitantes desta futurosa cidade collaborarão com as commissōes e farão jus ao agradecimento destas pelo exito alcançado" [14]. O que não impediu que parte da população reagisse à sua própria maneira: "As mulheres, muitas delas de véu na cabeça, rezavam o terço. Uma boa parte do povo pensava que o mundo ia acabar mesmo, de tanta história que se contou." [14].

No início do século XX, a imprensa desempenhava um papel, mesmo em pequenas cidades do interior do Brasil, que permitia acompanhar a rotina dos grandes acontecimentos, mas, sobretudo, os fatos que cercavam a vida cotidiana: "[a imprensa] oferece muitas notícias nacionais ou internacionais, mas se enraíza acima de tudo no ambiente imediato dos leitores. Sendo uma janela aberta para o mundo, ela é ao mesmo tempo a expressão de um espaço de convívio ampliado" [22]. Algumas vezes, a leitura do jornal era realizada em lugares públicos para que o maior número de pessoas se informasse sobre o que se passava na cidade. Era uma prática que também se dava no âmbito doméstico. Dessa forma, a rotina do evento do eclipse solar não foi acompanhada somente a olho nu, ela também foi mediada pela imprensa.

REVELAÇÃO E COMPARAÇÃO Outra questão que merece destaque é o local de revelação das chapas, também chamado de "gabinete escuro", que foi cercado de intensos cuidados. Era preciso garantir a qualidade da revelação das fotografias, passando por sucessivas verificaçôes ([18], 14 a 16 de maio de 1919). Um momento que traria resultados, provocando mudanças na forma de pensar os paradigmas da gravitação universal. Davidson e Crommelin ressaltaram: "As chapas ficaram nos seus suportes até serem reveladas. $\mathrm{O}$ processo de revelação foi efectuado em série durante a noite, todos os dias até 5 de junho" ([19], p. 80). O gabinete escuro apresentou as condições ideais para revelar as chapas fotográficas, já que seria um risco transportá-las. 
A primeira imagem só foi revelada às três horas da madrugada, por Davidson, depois de obter água suficientemente fria: “[...] A revelação tornou-se então possível, mas somente durante a noite. $\mathrm{O}$ amolecimento da gelatina dos filmes foi objeto de sérios cuidados, pois um deslocamento microscópico na revelação viciaria completamente os resultados. Esse obstáculo foi superado pelo uso de formalina e pela cuidadosa manipulação" [10]. Crommelin relata que o clima da região possuía temperatura da água normalmente acima de 25 graus centígrados. Crommelin observou que a qualidade da revelação só foi alcançada com a utilização de arcaicos utensílios de barro: "O único jeito foi recorrer a potes de barro usados comumente pela população", frios o suficiente para “[...] fazer a temperatura da água descer a quase 20 graus" [10, 23]. É possível perceber que mesmo com modernos aparelhos, como telescópios e celóstatos, as expedições enfrentaram um problema de aparente simplicidade: como resfriar a água para revelar as fotos? "Conseguir gelo não foi possível" [10].

No dia 7 de junho, quando o processo de revelação foi encerrado, a expedição britânica embarcou para Fortaleza [24], onde permaneceu até o dia 9 de julho, voltando depois para Sobral para realizar as chapas de comparação [25]. A expedição brasileira, por sua vez, depois do registro do eclipse teve "dia de descanso e de visitas" [26]. Retomados os trabalhos, era preciso desmontar os instrumentos [27] e partir para o Rio de Janeiro no Lloyd Brasileiro.

Foi preciso esperar alguns dias até que a experiência fosse concluída por completo. Os resultados dessas chapas serviriam para traçar uma comparação com as fotografias tiradas no dia do eclipse para observar as posições das estrelas e então confirmar de vez a teoria de Einstein [24]. Dessa maneira, os resultados não poderiam ainda ser confirmados, devendo-se afastar qualquer possibilidade de erro.

Crommelin e Davidson expuseram as condições para obter o material comparativo: apesar de terem sido tiradas com os mesmos instrumentos, as fotografias do eclipse de 29 de maio foram feitas durante o dia, enquanto as chapas de comparação $(14,15$, 17 e 18 de julho) foram obtidas no fim da tarde. Os britânicos, contudo, apresentaram uma boa argumentação para que as fotografias fossem aceitas para confirmar os registros obtidos: "Uma excelente característica inerente a estas fotografias é o facto de haver uma semelhança essencial entre as imagens de estrelas nos dois conjuntos de fotografias" ([19], p. 84). Além disso, as fotografias das chapas de comparação baseavam-se em uma "chapa-padrão", sendo intermediária entre as chapas do eclipse e as chapas de comparação.

RECONHECIMENTO Com número suficiente de fotografias para servir de referência, a equipe britânica começou a desmontar os equipamentos. Davidson e Crommelin partiram de Sobral no dia 22 de julho em direção à cidade de Camocim, para então seguir viagem com destino à Inglaterra, sendo que parte da bagagem ficou sob a responsabilidade dos senhores Nicolau e Carneiro para envio posterior. No relatório, os britânicos reconheceram o esforço do governo brasileiro: "Os observadores desejam agradecer [...] a ajuda inestimável que lhes foi prestada de modo a facilitar as viagens de ida e volta numa época particularmente difícil” ([19], p. 82). Eles chegaram a Greenwich em 25 de agosto de 1919.

Com a publicação do relatório final da expedição britânica veio a público o reconhecimento dos esforços que as autoridades sobralenses empreenderam para oferecer condições adequadas de trabalho aos observadores: "Estes foram tratados como hóspedes do Governo (que lhes facultou meios de transporte, alojamento e mão-de-obra)" [28]. Parte dessa satisfação e agradecimentos enfatizava as providências tomadas por Morize, à época diretor do Observatório Nacional do Rio de Janeiro. Não eram tão somente os observadores que estavam agradecidos. A imprensa da região afirmava que a população sentiu-se lisonjeada em receber os "[...] dois conhecidos sábios" [29]. Uma carta de agradecimento escrita pelo astrônomo real sir Frank Watson Dyson, vinda do Observatório Real em Greenwich, foi publicada no jornal Correio da Semana quase um ano após a observação do eclipse solar. Nela o cientista corroborou a impressão positiva que a expedição já manifestara sobre a hospitalidade do prefeito de Sobral [30].

Os resultados satisfatórios e a comprovação da hipótese geral da relatividade foram divulgados em uma sessão conjunta da Royal Society e da Royal Astronomical Society, na Inglaterra, em 6 de novembro de 1919. Uma série de artigos e conferências foi publicada a partir dessa data [31].

Muito do êxito da experiência em Sobral só foi possível devido à estrutura com que os observadores puderam dispor. Como ponto de observação, a cidade ofereceu às expedições um céu límpido, sem promessas de chuva. Para os habitantes de Sobral, o ano de 1919 anunciava a modernidade com a comprovação da teoria da relatividade de Einstein e também trazia de volta a infeliz perspectiva de um longo período de estiagem. Homens de ciência com seus sofisticados aparelhos estabeleceram uma nova maneira de a humanidade encarar sua relação com o tempo e o espaço.

Por fim, e não menos importante, este artigo propôs-se a observar o olhar da ciência sobre uma cidade localizada no "Norte do Brasil", apropriando-se de elementos da comunidade — como os potes de barro. A história da ciência tem um ponto de inflexão importante a partir da geografia e do clima. A seca é comum para quem vive em regiōes onde a má distribuição da chuva prejudica o modo de vida do sertanejo, no entanto, tal característica climática, apesar de adversa, foi propícia para esse acontecimento científico.

Joyce Mota Rodrigues, nascida em Tauá-CE, élicenciada em história pela Universidade Estadual Vale do Acaraú / Sobral - CE, especialista em história e cultura indígena afro-brasileira pela Ateneu e mestre em história social pelo Programa de Pós-Graduação em História Social da Universidade Federal do Ceará (UFC), com publicação do livro Entre telescópios e potes de barro: expediçōes científicas do eclipse solar na comprovação da teoria da relatividade em Sobral —CE / 1919 (Ed. - Curitiba: Appris, 2019). 


\section{ANOS DO ECLIPSE DE SOBRAL/ARTIGOS}

\section{NOTAS E REFERÊNCIAS}

1. As casas em que ficariam instalados eram da família Saboya, proprietária da fábrica de algodão em Sobral, as únicas com capacidade para acomodar os viajantes e os instrumentos. As duas residências foram cedidas pelo coronel Vicente Saboya e José Saboya de Albuquerque.

2. "Jockey-Club Sobralense". Correio da Semana. Sobral, 24 de agosto de 1918.

3. Dois intérpretes foram colocados à disposição dos ingleses desde o momento do desembarque em Camocim - CE e durante todo o tempo que a equipe britânica esteve na região: Leocádio Araújo, que estudara agricultura nos Estados Unidos e fazia parte da comissão agrícola a serviço do governo do estado do Ceará; e John Sandford, um norte-americano radicado na região. Segundo Crommelin, " $[$...] muito do nosso sucesso é devido ao seu confiável interesse e gentileza". Ver [10].

4. O interesse pelo tema surgiu na graduação, participando do projeto "Museu do Eclipse: Parque de Experimentos Interativos em Sobral", financiado pelo CNPq de maio/2007 a setembro/2008, em que atuei como bolsista.

5. “'Até a elevação da povoação à categoria de vila em 1773, o povoado manteve-se com o nome de Caiçara, quando então passou a chamar-se Vila Distinta e Real de Sobral. Uma ordem régia de 22 de julho de 1766 determinou a necessidade da existência de, no mínimo, 50 fogos na sede da povoação a ser transformada em vila. No início da década de setenta, a povoação já contava com 75 casas, o que indica uma relativa prosperidade, e com um núcleo estruturado que possibilitava a instalação de mais atividades e a atração de um número maior de pessoas". In: Barbosa, M. E. J.et al. Sobral - patrimônio nacional/Sobral - histórico e evolução urbana. Sobral, Prefeitura Municipal de Sobral, 2000. p. 14-15.

6. Hambúrguer, A. I. et al. (orgs.). As ciências nas relações Brasil-França (1850-1950). São Paulo: Universidade de São Paulo: Fapesp, 1996.

7. Paty, M.. "A recepção da relatividade no Brasil e a influência das tradições europeias". In: Hambúrguer, A. I. et al. (orgs.). As ciências nas relações Brasil-França (1850-1950). São Paulo: Universidade de São Paulo: Fapesp, 1996. p. 149.

8. Correio da Semana, A Lucta, A Ordem (Sobral), Folha do Littoral (Camocim), o Jornal, Jornal do Brasil, Jornal do Commercio (Rio de Janeiro).

9. Morize, H. "Resultados obtidos pela Commissão Brasileira do Eclipse de 29 de maio de 1919". Revista de Sciencias. Brasil: v. 4, n. 3, junho - julho 1920. Crommelin, A.; Davidson, C. R. “III - A expedição ao Sobral". Cottingham, E.; Eddington, A. S. "A expedição à Ilha do Príncipe". In: Eddington e Einstein: verificação experimental da teoria da relatividade generalizada na IIha do Príncipe. Santos. A. N.; Auretta C. (orgs.). 1a. ed. Lisboa: Gradiva, 1992.

10. Crommelin, A. "The eclipse expedition to Sobral". The Observatory (Provided by the Nasa Astrophysics Data System), v. 42, n. 544, 1919. p. 368-371 (Diário traduzido por Emerson Ferreira de Almeida, mestre em física pela Universidade Federal do Ceará, diretor técnico científico do Museu do Eclipse/ Secretaria da Cultura e Turismo de Sobral e professor da Universidade Estadual Vale do Acaraú UVA/Sobral/CE).

11. Observatory, Conquest (Davidson), Revista de Sciencias e Revista Trimensal do Instituto do Ceará.

12. Eddington, A. S.; Dyson, F. W.; Davidson, C. R. “Uma determinação da deflexão de luz pelo campo gravitacional do sol, a partir de observações realizadas no eclipse total de 29 de maio de 1919". In: Santos. A. N.; Auretta, C. (orgs.). Eddington e Einstein: verificação experimental da teoria da relatividade generalizada na IIha do Príncipe. 1a. ed., Lisboa: Gradiva, 1992.

13. Localizada no semiárido, Sobral foi escolhida porque está situada no lugar de maior sombreamento da Lua. A região pode possibilitar melhores condições de observação do céu, ou seja, é pouco provável ficar nublado na maior parte do ano, o que possibilita visualizar um grande número de estrelas brilhantes. Sobre isso, ver: Eisenstaedt, J.; Videira, A. A. P. "A prova cearense das teorias de Einstein". In: Ciência Hoje, v. 20, n. 115, nov./1995.

14. Serpa, E. "Sobral, Ceará. Aqui se provou que Einstein estava certo". Jornal do Brasil, Rio de Janeiro, 26 março de 1979.

15. "De Sobral - o eclipse do dia 29" (do correspondente). Folha do Littoral. Camocim, 8 de junho de 1919.

16. "Eclipse solar total de 29 de maio de 1919". Correio da Semana. Sobral, 17 de maio de 1919.

17. "O eclipse". A Lucta. Sobral, 4 de junho de 1919.

18. Morize, H. "Resultados obtidos pela Commissão Brasileira do Eclipse de 29 de maio de 1919". Revista de Sciencias. Brasil: v. 4, n. 3, junhojulho 1920.

19. Crommelin, A.; Davidson, C. R. "III - A expedição ao Sobral". In: Santos, A. N.; Auretta, C. (orgs.). Eddington e Einstein: verificação experimental da teoria da relatividade generalizada na Ilha do Príncipe. 1a. ed. Lisboa: Gradiva, 1992.

20. "A noite esteve quente"; "Dia muito quente"; "Muito mosquito na primeira da noite. Céu claro. Vento quase nulo"; "Levantei-me às $6 \mathrm{~h}$ após noite má devido aos mosquitos". Ver ([18], 14 a 28 de maio de 1919).

21. "Eclipse solar total de 29 de maio de 1919". Correio da Semana. Sobral, 24 de maio de 1919.

22. Prost, A. “Transições e interferências". In: Prost, A; Vicent, G. (orgs.). História da vida privada. 5: da Primeira Guerra a nossos dias. São Paulo: Companhia das Letras, 1992. p. 42. Trad: Denise Bottmann.

23. Sobre isso, há uma explicação química: “Em algumas regiões do Brasil, principalmente aquelas com pouco acesso à energia elétrica, é comum as pessoas utilizarem potes de barro para conservar água a uma temperatura um pouco mais fria que a do ambiente. Este fenômeno, que para muitos ainda é considerado uma "crendice popular", pode ser explicado também pela compreensão do que ocorre nas mudanças de estados físicos da matéria e na troca de calor entre dois corpos. A porosidade do barro permite que uma pequena parte da água contida no pote, ao passar por esses poros e entrar em contato 
com o ambiente externo, passem do estado líquido para o estado gasoso (evaporação). Este processo de evaporação da água líquida (menor energia cinética) para o estado de vapor (maior energia cinética) necessita absorver energia para ocorrer. No caso do pote de barro, a água que evapora, retira energia (calor) do pote e do restante da água que não evaporou, fazendo com que, ao perder energia, tanto o pote como a água, se resfriem". Leão, M. "Uma conversa sobre 'coisas' da química". Disponível em: http://marceloufrpe.blogspot. com.br/2010/08/agua-fria-em-pote-de-barro.html. Acesso em: 01 de setembro de 2012.

24. "O eclipse total do Sol". Correio da Semana, Sobral, 7 junho de 1919.

25. Sobre o período, sabe-se apenas que Davidson e Crommelin ficaram hospedados no Seminário Diocesano de Fortaleza. Studart, G. "Ephemerides Cearenses". Revista Trimensal do Instituto do Ceará. Anno XXXV, 1921, p.339-348. Disponível:http://institutodoceara.org. br/Rev-apresentacao/RevPorAno/1921/1921-EphemeridesCearenses1919e1920.pdf. Acesso em 11 de agosto de 2011.

26. "Começa-se a desmontar os instrumentos. Revelam-se as fotografias. As da objetiva de Zeiss f/35 tomadas sem movimento de relojoaria deram três placas instantâneas regulares. As da teleobjetiva deram três placas instantâneas regulares. As da teleobjetiva de Zeiss não deram nada; [...] A do espectrógrafo de quartz de Heyde nada deu, nem mesmo o espectro de comparação. Parece que ou o caixilho não foi aberto ou a placa foi nela invertida, ficando para a frente a capa do antehalo que é opaca. Os dois pequenos espectrógrafos deram os limbos de coroa sobre um fundo de espectro contínuo." ([18], 30 e 31 maio de 1919).

27. Durante a desmontagem dos instrumentos, a expedição britânica marcou as posições originais dos aparelhos para que fossem tiradas chapas de comparação com o máximo de fidedignidade quanto ao posicionamento. Os espelhos e os mecanismos dos relógios precisariam estar na mesma posição. A importância dessas chapas, era validar o experimento a partir da observação do Sol em outra posição no mês de julho. Ver [24, p.82].

28. Dyson, F. W.; Eddington, A. S.; Davidson, C. R. V - Conclusões Gerais, 1920. p.130-131.

29. "Drs. Crommelin e Davidson". Correio da Semana, Sobral, 26 julho de 1919.

30. "[...] Londres, 25 de novembro, de 1919. - Caro senhor, como Presidente do Comittee da Sociedade Real e da Real Sociedade Astronômica que organizou a expedição para observação do Eclipse de 29 de maio de 1919, escrevo-Ihe para agradecer a grande assistência dada por V.S. aos observadores. [...] Eu conheço de experiência própria das difficuldades de uma expedição de eclipse e posso avaliar assim o valor do auxilio que V.S. dispensou tão bondosamente". "Eclipse de 29 de maio de 1919". Correio da Semana, Sobral, 24 janeiro de 1920.

31. " [...] os Physicos e Astronomos Inglezes estão ainda comentando o facto e ainda o farão por algum tempo". "Eclipse de 29 de maio de 1919". Correio da Semana, Sobral, 24 janeiro de 1920.

\section{- ERLIPSE SOLAR DE 1919. EINGTEN E A MUDIA BRASILEIRA}

\author{
Ildeu de Castro Moreira
}

O ECLIPSE DE 1919 E SEU IMPACTO NA CIÊNCIA Neste ano se comemora em todo o mundo o centenário das observaçôes astronômicas realizadas durante o eclipse solar de 29 de maio de 1919 . As medidas da deflexão da luz das estrelas na borda do Sol constituíram uma evidência muito forte para a confirmação e a aceitação da teoria da relatividade geral de Einstein. Essa teoria alterou profundamente a nossa visão sobre o universo. Ela suplantou a teoria gravitacional que Newton havia formulado cerca de dois séculos antes e foi um acontecimento de extraordinária importância na ciência. As observações decisivas foram feitas por astrônomos britânicos em Sobral (Ceará) e na Ilha do Príncipe (África Ocidental), então pertencente a Portugal.

Em 1915, Einstein havia elaborado uma teoria que permitia incluir a gravitação no âmbito das ideias da relatividade [1]. Ele chegou à sua teoria da relatividade geral baseado na ideia de que a gravitação resulta da alteração da geometria do espaço-tempo pela presença da matéria. A partir daí previu que a luz das estrelas, ao seguir a trajetória mais curta no espaço-tempo curvo, sofreria uma deflexão nas vizinhanças do Sol por um valor que seria o dobro do previsto pela teoria newtoniana: o ângulo de deflexão deveria ser aproximadamente 1,74" (segundos de arco).

A partir de 1917, astrônomos britânicos iniciaram os preparativos para observar o eclipse solar que aconteceria em 29 de maio de 1919 e testar a previsão de Einstein. Para isso, organizaram duas expediçôes para regiôes nas quais o eclipse seria total: uma, com Arthur Eddington e Edwin Cottingham, para a Ilha do Príncipe, e outra, com Charles Davidson e Andrew Crommelin, para Sobral. A escolha de Sobral como ponto de observação no Brasil foi feita por Henrique Morize, diretor do Observatório Nacional do Rio de Janeiro. Ele também ficou encarregado de providenciar a infraestrutura para as expediçôes estrangeiras que viriam para o Brasil.

Em Sobral, no dia do eclipse, apesar do tempo inicialmente nublado, as condiçôes ficaram boas na hora do evento, que ocorreu às 8:56 h e durou cerca de cinco minutos. As 17 fotografias tiradas com o uso do telescópio com maior diâmetro tiveram um problema de foco e não ficaram boas. Sete chapas, provenientes de um telescópio com lente de quatro polegadas, foram consideradas muito boas; sete estrelas apareciam nelas. Já na Ilha do Príncipe o tempo esteve chuvoso e poucas fotografias foram tiradas; delas, só duas puderam ser aproveitadas, e levaram a resultados mais incertos que os de Sobral.

A comissão brasileira em Sobral, liderada por Henrique Morize, fez observações sobre a coroa solar durante o eclipse. Medidas do magnetismo terrestre e de eletricidade atmosférica foram feitas pelos norte- 